\title{
Desenvolvemento de competencias en estudantes implicados e non implicados nunha experiencia aprendizaxe-servizo
}

\author{
Ares-Pernas, Ana; Abad, María José; Montero, Belén \\ Departamento de Física e Ciencias da Terra. Campus de Ferrol. Universidade da Coruña
}

\section{RESUMO}

Neste traballo empregáronse dúas metodoloxías; 0 aprendizaxe baseado en proxectos (ABP) e 0 aprendizaxe-servizo (ApS) para abordar as competencias transversais da materia Fundamentos de Física de primeiro curso do Grao en Enxeñería de Deseño Industrial e Desenvolvemento do Produto. 0 obxectivo do traballo era valorar o impacto que tiña nos estudantes a participación nun ou noutro proxecto e avaliar as distintas competencias acadadas en función da metodoloxía docente empregada. Nas dúas metodoloxías o estudante é protagonista da súa propia aprendizaxe, favorecese a aprendizaxe cooperativa e colaborativa e, ademais, a avaliación de competencias resulta máis sinxela para 0 docente, pois pode seguir ao estudante durante todo o proceso. $0 \mathrm{ApS}$ aporta un valor engadido xa que se realiza ademais un servizo á comunidade contribuíndo así a formar os estudantes tamén en valores. A pesar de que todos acadaron as competencias académicas esperadas e outras coma mellora da autoconfianza ou capacidade para a toma de decisións, aqueles que estaban implicados na actividade ApS presentaron outras máis persoais coma empatía, aprender dos que son diferentes ou recoñecemento do seu potencial coma cidadáns e axentes do cambio social. Distintos proxectos ApS deron lugar tamén a distintas competencias.

PALABRAS CHAVE: competencias, aprendizaxe-servizo, aprendizaxe baseado en proxectos, Física, exclusión social. 


\section{CITA RECOMENDADA:}

Abad, M. J., Ares-Pernas, A., Montero, B. (2018). Desenvolvemento de competencias en estudantes implicados e non implicados nunha experiencia aprendizaxe-servizo. En E. de la Torre Fernández (ed.) (2018). Contextos universitarios transformadores: retos e ideas innovadoras. II Xornadas de Innovación Docente. Cufie. Universidade da Coruña (páx. 139-154).

DOI capítulo: https://doi.org/10.17979/spudc.9788497496780.139

DOI libro: https://doi.org/10.17979/spudc.9788497496780

\section{ABSTRACT}

In this work, two methodologies were used; project-based learning (PBL) and service -learning (S-L) to address the transversal skills of the subject "Fundamentals of Physics". This subject is taught in the first year of the Degree in Engineering of Industrial Design and Product Development. The objectives of the work were; to assess the impact on the undergraduate students and to evaluate the skills reached, depending on the type of project in which they were involved. In both methodologies, the student is the protagonist of their own learning process, cooperative and collaborative learning are favoured and the skills evaluation is easier for the teacher, who follow the student during the whole process. Besides, S-L brings added value because a service to the community is performed, which helps to educate students also in values. All the students achieved the programmed skills and others, as self-confident or ability to take decisions. But besides, the undergraduate students involved in S-L activity achieved other personal skills, such as empathy, learning from those who are different or recognition of their potential as citizens and agents of social change. Different S-L projects also lead to different skills.

KEY WORDS: skills, service-learning, project-based learning, Physics, social exclusion. 


\section{INTRODUCCIÓN}

A Física é unha disciplina presente como materia de formación básica nos primeiros cursos das enxeñerías. Nesta materia as prácticas son obrigatorias e deben programarse como unha parte esencial da mesma xa que permiten aos estudantes aplicar os coñecementos explicados na aula a casos reais e traballar competencias transversais como a capacidade para 0 deseño e redacción de proxectos, traballo colaborativo e outras máis difíciles de avaliar coma comunicación efectiva ou falar en público, entre outras.

Para abordar este tipo de competencias existen diversas metodoloxías docentes que poden resultar moi útiles. Unha delas é o aprendizaxe baseado en proxectos (ABP) que é unha estratexia de aprendizaxe onde 0 alumno é o principal protagonista e no que se reta ao mesmo a resolver un problema e demostrar a súa solución para unha audiencia externa (Holubova 2008). Os estudantes nesta metodoloxía colaboran nunha investigación, o que implica adquirir competencias como a capacidade de resolución de problemas, comunicación, colaboración e cooperación e pensamento crítico (Pinar et al. 2011; Bobrof \& Bouquet 2016).

Ademais a Universidade ten 0 obxectivo de formar titulados non só altamente cualificados para o desenvolvemento da súa profesión, senón que ademais debe contribuír a preparar profesionais dotados de principios éticos e valores (Withley \& Yolder 2015). A metodoloxía aprendizaxe-servicio (ApS) é unha ferramenta educativa que facilita esta labor xa que comparte co ABP a adquisición de competencias transversais pero ademais os estudantes realizan un servicio á comunidade (Latib et al. 2017, Dienhart et al. 2016). Ao igual que na metodoloxía ABP os estudantes constrúen o seu aprendizaxe a través da experiencia xa que a metodoloxía leva tamén implícitos procesos de investigación, preparación, acción, demostración e avaliación. A maiores, o ApS inclúe unha parte importante de reflexión, por parte do estudante, acerca do que o seu papel supón como axente de cambio na comunidade á cal el mesmo está servindo.

Neste traballo estas dúas metodoloxías aplicáronse para abordar a parte práctica da materia Fundamentos de Física do Grado en Enxeñaría de Deseño Industrial e Desenvolvemento do 
Produto. Escolléronse estas dúas metodoloxías polas súas similitudes, antes mencionadas, pero 0 feito de que no ApS se realice un servicio á comunidade, incluíndo polo tanto 0 contacto con unha entidade externa e con grupos desfavorecidos, pode facer que os estudantes adquiran outras competencias diferentes ca os que están envoltos nunha experiencia ABP (Seban 2013). 0 obxectivo deste traballo foi analizar as competencias acadadas polos estudantes tralas dúas experiencias e o impacto que sobre eles tivo, o feito de estar envolto nunha ou outra metodoloxía educativa.

\section{DESCRICIÓN DA EXPERIENCIA}

\subsection{Planificación das actividades}

Esta actividade desenvolveuse entre os meses de Febreiro e Xuño do curso 2016/2017 co alumnado da materia Fundamentos de Física de $1^{\text {er }}$ curso do Grao en Enxeñaría de Deseño Industrial e Desenvolvemento do Produto da Universidade da Coruña (UDC).

Nesta actividade, como se comentou previamente, empregáronse dúas metodoloxías docentes para a avaliación de competencias transversais no alumnado: ApS e ABP.

Ó principio do cuadrimestre, a profesora responsable da materia presentoulle ao alumnado as competencias transversais que deberían adquirir para superar a materia (Táboa 1) e as opcións de traballo práctico que se lles ofrecía para ese fin; o ApS e o ABP, introducíndolles cada metodoloxía.

Os estudantes que participasen na actividade ApS faríano de forma voluntaria e realizarían un servicio á comunidade, concretamente a dúas entidades; Cáritas Diocesana de MondoñedoFerrol (en adiante Cáritas) e Asociación de Amigos e Familiares de Enfermos Mentais-AFAES Ferrol (en adiante AFAES). En Cáritas contaban cun grupo de nenos que formaban parte do programa "Medrando en Familia" da entidade, os cales presentaban un denominador común; un baixo rendemento académico e desmotivación á hora de aprender. En AFAES, os usuarios eran persoas con enfermidade mental, concretamente esquizofrenia e a entidade transmítenos 
a necesidade de promover 0 emprego, a inclusión social e a ocupación neste grupo. 0 servizo que ían a realizar os estudantes debía aportar algunha solución a esas necesidades.

Por outra parte, os estudantes que non se involucrasen na actividade ApS, participarían de forma obrigatoria no proxecto ABP. Deberían de realizar un proxecto e se lles propón coma reto 0 "Deseño dunha práctica". Os estudantes debían seleccionar de entre os contidos de Dinámica algún concepto, teoría, principio, etc... que lles interesase, deseñar unha práctica que 0 explicase e preparar un póster onde se resumise 0 traballo. Posteriormente, presentaríase aos demais compañeiros e a un comité científico nunha sesión de pósters ó final do cuadrimestre.

Tras explicar aos estudantes as opcións, a resposta para participar na actividade ApS foi masiva e houbo de seleccionarse por sorteo 0 número de estudantes necesario para a actividade, neste caso 14 estudantes, e o resto, 51 estudantes, participaron na actividade ABP.

A4. Traballar de forma efectiva como individuo e como membro de equipos diversos e multidisciplinares

A7. Capacidade para o deseño, redacción e dirección de proxectos, en todas as súas diversidades e fases

B4. Traballar de forma colaborativa. Coñecer as dinámicas de grupo e o traballo en equipo

B9. Comunicarse de forma efectiva nun entorno de traballo

C1. Expresarse correctamente, tanto de forma oral coma escrita, nas linguas oficiais da comunidade autónoma

C4. Desenvolverse para o exercicio dunha cidadanía aberta, culta, crítica, comprometida, democrática e solidaria, capaz de analizar a realidade, diagnosticar problemas, formular e implantar solucións baseadas no coñecemento e orientadas ao ben común.

\section{Táboa 1. Competencias transversais da materia}

Unha vez seleccionados os estudantes participantes, fixouse 0 cronograma das actividades, decidiuse cos estudantes de ApS o tipo de servizo a realizar en cada entidade e presentóuselles a metodoloxía de avaliación en cada caso. 0 cronograma das actividades foi moi similar en ambas metodoloxías (ver Táboa 2).

Unha descrición máis detallada das actividades ApS pode verse na Táboa 3. 


\begin{tabular}{|l|l|}
\hline Semana 1 & $\begin{array}{l}\text { O grupo selecciona 0 contido que lles interesa para 0 deseño da práctica } \\
\text { (ABP) } \\
\text { Deseño do servizo para cada entidade (ApS) }\end{array}$ \\
\hline Semanas 2-10 & $\begin{array}{l}\text { Investigación. Selección de materiais. Deseño e posta en práctica (ABP) } \\
\text { Deseño dos materiais, experimentos, prácticas (ApS) } \\
\text { Sesións de titorización, e revisión }\end{array}$ \\
\hline Semanas 11-12 & $\begin{array}{l}\text { Preparación do produto (Póster) (ABP) } \\
\text { Ensaio final do taller (ApS) }\end{array}$ \\
\hline Semana 13 & $\begin{array}{l}\text { Presentación ao público (resto estudantes, comité avaliación) (ABP) } \\
\text { Realización do taller cos usuarios das entidades (ApS) }\end{array}$ \\
\hline Toda a actividade & $\begin{array}{l}\text { Avaliación de competencias (observación e rúbrica) } \\
\text { Reflexión }\end{array}$ \\
\hline Ao final & $\begin{array}{l}\text { Avaliación da actividade: autoavaliación, coavaliación, avaliación por parte do } \\
\text { docente e do comité (ABP) } \\
\text { Informe final da actividade que inclúa as reflexións de todos os axentes } \\
\text { implicados (ApS) } \\
\text { Enquisa final. Análise final de fortalezas e debilidades (Feedback)- Puntos de } \\
\text { mellora e redeseño de actividade }\end{array}$ \\
\hline
\end{tabular}

Táboa 2. Cronograma das actividades. Entre parénteses a actividad á que pertence

\begin{tabular}{|l|c|c|}
\hline & Grupo CÁRITAS & Grupo AFAES \\
\hline $\mathrm{N}^{0}$ de estudantes & 8 & 6 \\
\hline $\mathrm{N}^{0}$ de usuarios & 18 nenos (10-15 años) & 32 adultos \\
\hline $\begin{array}{l}\text { Características } \\
\text { dos usuarios }\end{array}$ & $\begin{array}{c}\text { Risco exclusión social } \\
\text { Alto fracaso escolar } \\
\text { Baixa autoestima } \\
\text { Desinterese nos estudos }\end{array}$ & $\begin{array}{c}\text { Risco exclusión social } \\
\text { Problemas para relacionarse } \\
\text { Baixa autoestima }\end{array}$ \\
\hline $\begin{array}{l}\text { Obxectivos do } \\
\text { proxecto }\end{array}$ & $\begin{array}{c}\text { Estimular a curiosidade e 0 } \\
\text { interese pola ciencia } \\
\text { Fomentar o pensamento crítico }\end{array}$ & $\begin{array}{c}\text { Promover o emprego, a inclusión social e a } \\
\text { ocupación dos pacientes. } \\
\text { Promover o reciclado e o coidado do } \\
\text { medioambiente }\end{array}$ \\
\hline Servizo & $\begin{array}{c}\text { Os estudantes imparten } \\
\text { conceptos básicos de Física } \\
\text { (densidade, presión, viscosidade, } \\
\text { flotación, óptica) a través de } \\
\text { xogos e experimentos de } \\
\text { laboratorio }\end{array}$ & $\begin{array}{c}\text { Os estudantes imparten un taller para } \\
\text { ensinarlles a fabricar novos produtos, que } \\
\text { ponden ven mercados solidarios) a } \\
\text { partir de residuos plásticos } \\
\text { Imparten ademais nocións de separación } \\
\text { de residuos e reciclaxe }\end{array}$ \\
& $\begin{array}{c}\text { Promoven a participación dos usuarios } \\
\text { para favorecer a comunicación }\end{array}$ \\
\hline
\end{tabular}

Táboa 3. Descrición das experiencias ApS 
Durante 0 desenvolvemento das actividades usáronse diferentes ferramentas para analizar os resultados. Tanto na actividade ApS coma na ABP avaliáronse as competencias dos estudantes mediante a utilización dunha rúbrica. Deste xeito, avaliáronse as competencias en distintos puntos da actividade e ao final da mesma, e tamén avaliouse tanto ao grupo coma ao alumno de forma independente.

No caso da actividade ABP, esta mesma rúbrica foi empregada polo comité avaliador, formado por 3 profesoras do Departamento de Física e Ciencias da Terra e unha profesora do Grupo de Polímeros para avaliar ao alumnado e ao grupo, o día da sesión de pósters.

A observación do alumno e do grupo durante todo o proceso foi crucial na avaliación. Trala actividade, a análise cuantitativa dos resultados fíxose mediante unha enquisa que, no caso da actividade $A B P$, realizouse ao alumnado implicado e, no caso do ApS realizouse aos estudantes, aos usuarios das entidades; tanto adultos coma nenos, ás entidades e ás profesoras implicadas na actividade. Nas enquisas, adaptadas no caso dos nenos e os adultos con enfermidade mental, preguntouse acerca dos contidos, a metodoloxía e a organización do curso como se verá máis adiante na parte dos resultados.

É moi importante salientar que, no caso da actividade ApS, ademais da análise cuantitativa, resulta imprescindible a análise cualitativa da actividade. Para a realización desa análise recolléronse as reflexións do alumnado antes da actividade, durante e despois da actividade. Os comentarios do alumnado guiáronse coa axuda dunhas preguntas reflexivas (ver exemplos na Táboa 4) e recollidas de forma escrita.

Por outra banda, para o correcto deseño e funcionamento da actividade ApS foi imprescindible a realización de reunións, entre os axentes implicados, en distintos puntos da actividade. No inicio, fíxose unha reunión entre a entidade, estudantes e profesores para enfocar o servizo. $\mathrm{Na}$ metade da experiencia, a tutorización e o seguimento foron imprescindibles como apoio aos estudantes e fixéronse ata catro reunións, entre profesores e alumnado. Obviamente este punto tamén foi imprescindible no caso da actividade ABP tal e como recolle a Táboa 2. Ao finalizar a experiencia, as reunións entre todos os axentes implicados na actividade, 
profesor/alumnado e profesor/entidades, foi tamén moi enriquecedora á hora de analizar os puntos débiles e fortes e redeseñar a actividade de cara aos seguintes cursos. No caso da actividade ApS, esta avaliación final resulta moito máis rica porque implica a participación de axentes externos (as entidades e os usuarios das mesmas). No caso do ABP, os puntos fortes e débiles só poden ser analizados polos axentes internos implicados na actividades, profesores e alumnado.

\begin{tabular}{|l|}
\hline Ao inicio da actividade \\
\hline Por qué te animaches a participar no ApS? Qué esperas gañar con esta experiencia? \\
\hline Pensas que che vai ser máis sinxelo acadar as competencias da materia? \\
\hline Qué competencias e habilidades cres que necesitas para traballar coa entidade? \\
\hline Pensas que o servizo será útil á comunidade? \\
\hline Durante a actividade \\
\hline Cómo te sentes traballando cos compañeiros e cos usuarios? \\
\hline $\begin{array}{l}\text { Qué necesidades ou problemas detectas nos usuarios agora que os coñeces? Queres aportar } \\
\text { algunha solución ao respecto? }\end{array}$ \\
\hline Ao final da actividade \\
\hline Pensas que as túas accións tiveron impacto nos usuarios e na entidade? \\
\hline Cómo afectou a actividade ás túas competencias, habilidades, crenzas, sentimentos, xuízos...? \\
\hline
\end{tabular}

Táboa 4. Preguntas reflexivas

\subsection{Actividade ABP}

Nesta actividade participaron 51 estudantes divididos en grupos de 2-3 de xeito que realizaron un total de 18 proxectos. Os estudantes traballaron conceptos como: Poleas, Forzas, Elasticidade, Lei de Hooke, Equilibrio, Momento de torsión, etc... deseñando en cada caso, un experimento que ilustrase cada concepto e preparando un póster que resumise as súas investigacións (ver exemplo na Figura 1).

No póster, os estudantes presentaban unha introdución do concepto teórico, despois enumeraban 0 material necesario para 0 experimento e a metodoloxía para realizalo e remataban coa presentación de resultados e a discusión dos mesmos e as principais conclusións obtidas. 
0 día da sesión de pósters os estudantes debían de colocarse diante do póster para defendelo cando o comité científico lles fixese algunha pregunta (Figura 2).

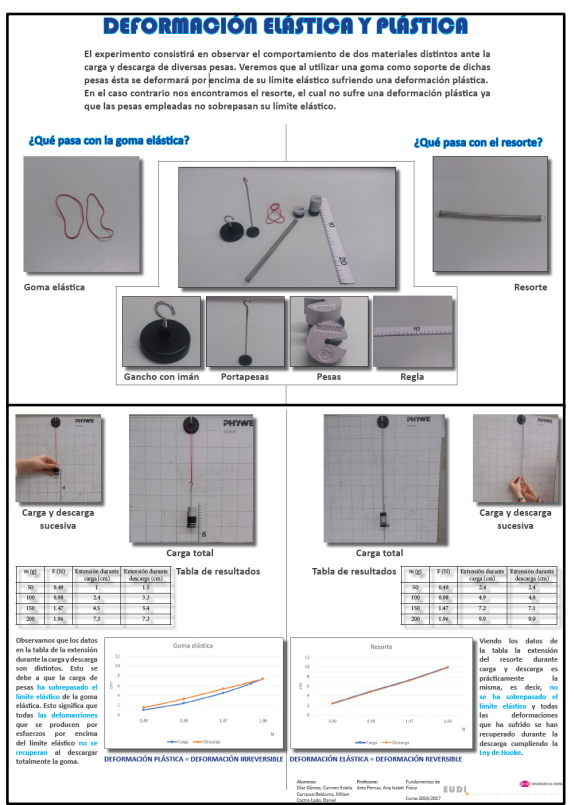

Figura 1. Exemplo de póster presentado polos estudantes de ABP

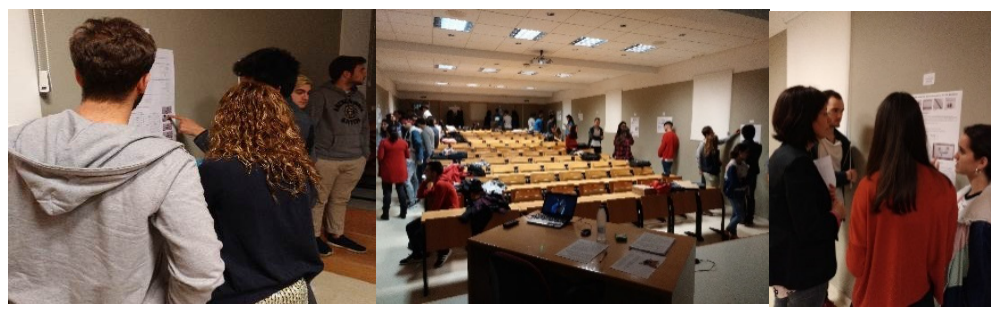

Figura 2. Imaxes da sesión de pósters

\subsection{Actividade ApS nenos CÁRITAS}

Participaron 8 estudantes divididos en dous grupos e prepararon distintos experimentos aos que puxeron nomes divertidos. Os estudantes tiveron total liberdade á hora de seleccionar os experimentos e os conceptos a traballar, sempre e cando fosen axeitados ao nivel académico dos nenos de entre 10 e 15 anos. Os estudantes facían en primeiro lugar o experimento para 
captar a atención dos nenos, despois discutían con eles que era o que se observaba e a que podería ser debido ese fenómeno, para posteriormente explicarlles o concepto físico reflexado no experimento (Figura 3). Algúns dos conceptos traballados e algún dos experimentos foron os seguintes:

- Centro de gravidade e equilibrio: "Os paus máxicos"

- Principio dos vasos comunicantes: "Enchendo botellas"

- Lentes. Ollo humano e enfermidades ópticas: "Construíndo un Cinexín"

- Ondas sonoras: "¿Queres ver como é a túa voz?" "Apagando o lume"

- Máquinas simples: "Minimizando o esforzo"

- Conservación da enerxía: "A lata búmerang"

- Presión aire, rozamento: "0 globo que levita"

- Lei da inercia, flotación, densidade, empuxe: "Xogando con ovos"

- Tensión superficial: "Maxia con auga"

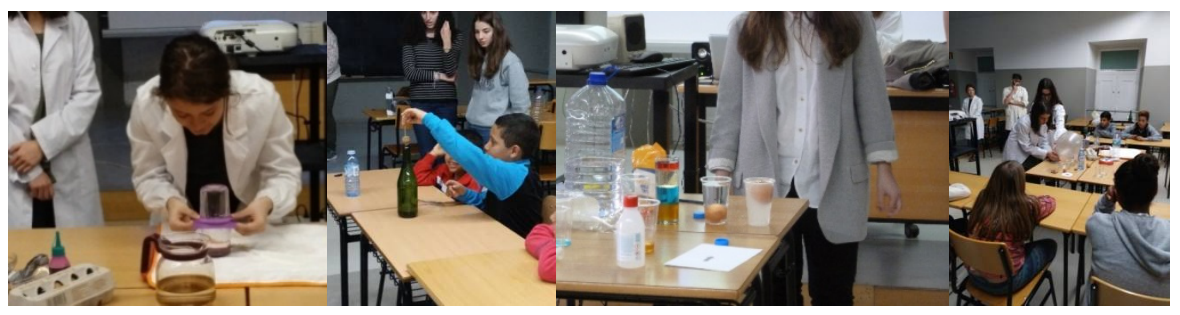

Figura 3. Imaxes do grupo CÁRITAS

\subsection{Actividade ApS AFAES}

Os 6 estudantes empezaron explicando aos usuarios o que facían na súa titulación e como 0 reciclaxe, a redución e a reutilización eran puntos básicos no deseño de novos produtos. Despois faláronlles do que é un plástico, tipos de plásticos, identificación dos mesmos e os seus usos máis comúns. Para manter a atención dos usuarios, con forte medicación, os estudantes intercalaron un xogo de separación de residuos no que os usuarios participaron moi activamente. Para rematar a parte teórica do curso os estudantes faláronlles da empresa 
SOGAMA, como xestora de residuos e da importancia que ten a separación nas casas para favorecer a súa labor. Na segunda parte do taller os estudantes dividíronse en seis equipos de maneira que cada un se encargaba dun grupo e repartiron os usuarios nos grupos. Cada grupo fabricou unha peza reciclada:

- Pendentes e colgantes reutilizando botellas de xampú

- Soportes para móbiles a partir de botellas de xampú

- Estoxo en forma de mazá con botellas de refresco

- Macetas e flores con vasiños de café e botellas de auga

- Lámpada con bolsas do supermercado

- Lapiseiro con tapóns de botellas

Na Figura 4 pode verse 0 cartel de promoción do curso, algún momento do taller e un documento guía que os estudantes prepararon para a parte práctica do taller.

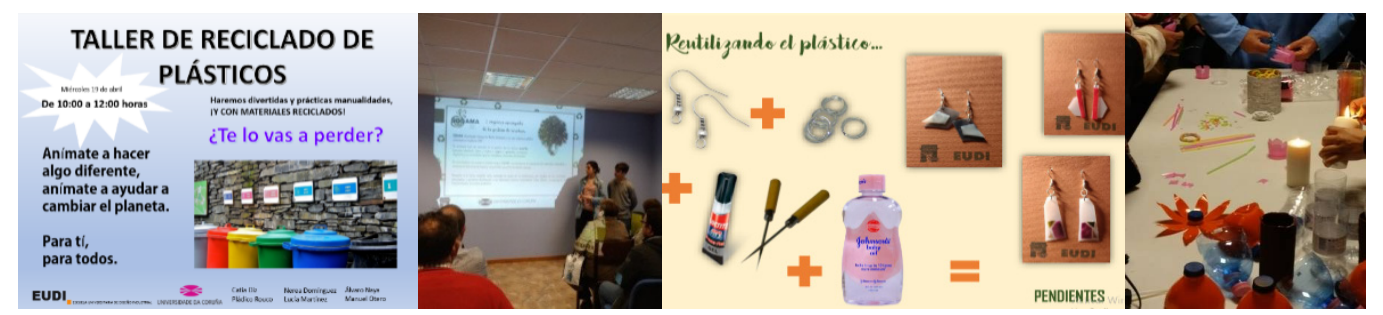

Figura 4. Imaxes do grupo AFAES

\section{RESULTADOS}

Para a análise dos resultados tivéronse en conta todas as evidencias recollidas durante a realización do proxecto e das que xa se falou previamente tanto dende 0 punto de vista cualitativo (reflexións, reunións) coma cuantitativo (enquisas). Aínda que se van a discutir todos os aspectos relacionados co traballo, a análise dos resultados vai centrarse fundamentalmente na parte das competencias que era o obxectivo deste traballo.

Dende 0 punto de vista cuantitativo, nas enquisas constatouse unha grande satisfacción por parte dos estudantes con todos os aspectos relacionados coa convocatoria (tempo, medios, 
información), obxectivos (aprendizaxe, currículo, expectativas, habilidades), reflexión, duración e coordinación por parte do titor, como se pode ver na Figura 5a, pero tamén por parte dos usuarios (Figura $5 b$ ). Neste caso preséntanse os resultados para os estudantes que traballaron en ApS cos nenos e tamén os resultados das enquisas aos nenos, pero en tódolos outros casos, estudantes ABP e estudantes ApS con adultos o grao de satisfacción foi moi similar con maioría de respostas "totalmente de acordo" ou "de acordo" e con maioría de respostas afirmativas no caso dos adultos.
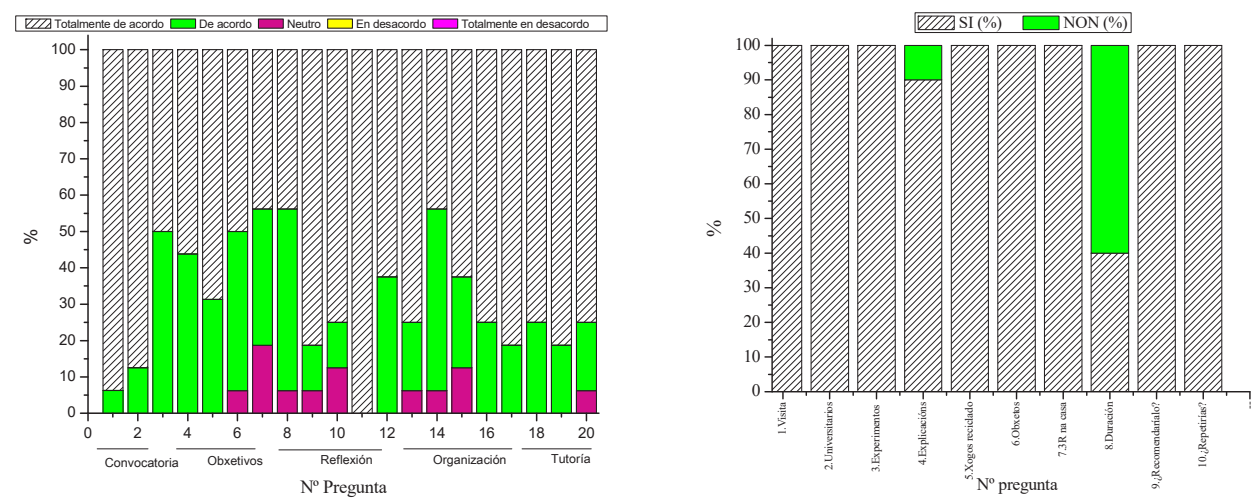

Figura 5. a) Resultados enquisa estudantes ApS nenos; b) Resultados enquisa nenos Cáritas

En canto ás entidades colaboradoras CÁRITAS e AFAES tamén mostraron a súa satisfacción e continuarán a colaborar en actividades ApS o vindeiro curso. Só no caso de AFAES destacaron un punto débil que foi o elevado número de usuarios participantes nunha mesma xornada.

En canto ao análise cualitativo das reflexións dos estudantes involucrados en experiencias ApS as principais motivacións para participar na experiencia foron o feito de traballar en grupo, 0 contacto cos nenos, aprender para ensinar, practicar conceptos teóricos da aula e axudar a persoas desfavorecidas. Durante a actividade as preocupacións dos estudantes estaban relacionadas co feito de non cumprir os obxectivos das entidades ou decepcionar aos usuarios o que aumentou a súa implicación no proxecto. Despois da experiencia algunhas das reflexións recollidas dos estudantes foron as seguintes: 
"Aínda que pareza mentira dúas horas son máis que suficientes para por os pés na terra e madurar" (Estudante ApS AFAES)

"Un usuario era enxeñeiro coma nós... unha inxección de realidade devastadora" (Estudante ApS AFAES)

"A reflexión persoal supuxo case máis que os conceptos teóricos que queríamos transmitir" (Estudante ApS AFAES)

"Cando tes que ensinar aprendes moito máis. 0 traballo en grupo tamén é moi bo para aprender de e con os compañeiros" (Estudante ApS AFAES)

"0 aprendizaxe-servizo é necesario para a nosa formación" (Estudante ApS NENOS)

"É moi difícil manter a atención do público, agora entendo aos meus profesores" (Estudante ApS NENOS)

"Síntome orgullosa de ter participado cos meus compañeiros nesta actividade e transmitir os meus coñecementos aos nenos" (Estudante ApS NENOS)

As reflexións recollidas dos usuarios indican tamén o moito que lles gustou a experiencia, 0 que aprenderon cos estudantes e no caso dos nenos destacaron que cos experimentos entenderan cousas que non entenderan na aula e que estudiar ciencias con este tipo de prácticas era moito máis sinxelo.

En canto ás competencias académicas todos os estudantes acadaron as competencias planificadas na guía docente da materia o que se puido constatar cos resultados extraídos das rúbricas. Facendo unha análise máis profunda das evidencias, puidéronse identificar as competencias desenvolvidas polos estudantes en cada proxecto e que aparecen na Táboa 5. Ademais das competencias esperadas e que figuraban na rúbrica (1-6) os estudantes acadaron outras coma "medrar en autoestima e confianza", "recoñecer o seu potencial" ou "toma de decisións e solución de problemas" que non se acadarían nunha simple práctica guiada na aula. Ademais é moi importante 0 feito de aprender a través da experiencia, os estudantes cometen erros e corríxenos durante o proceso o que favorece a súa aprendizaxe, xa que 0 erro é un dinamizador moi importante da aprendizaxe. 
Os estudantes envoltos nas actividades ApS desenvolveron ademais outras competencias de tipo máis persoal coma "sentido da responsabilidade", "empatía" ou "ser autónomo e emprendedor". Cabe destacar o feito de que os estudantes que traballaron cos nenos atopáronse 0 mesmo día do taller con nenos de entre 5 e 10 anos que viñeran con os seus irmáns e tiveron que adaptar as súas explicacións in situ para que todos os entenderan, este feito, estresante ao principio, fixo que os estudantes medrasen en autonomía e autoestima ao darse conta de que podían reaccionar ben aos imprevistos.

No caso dos estudantes que traballaron co grupo máis desfavorecido de persoas con enfermidade mental apareceron outras competencias coma "ser tolerante" e "aprender de aqueles que son descoñecidos".

\begin{tabular}{|c|c|c|c|}
\hline & $\begin{array}{c}\text { ApS nen@s } \\
\text { CÁRITAS }\end{array}$ & $\begin{array}{c}\text { ApS adultos } \\
\text { AFAES }\end{array}$ & $\mathrm{ABP}$ \\
\hline 1.Traballar en equipo & $\checkmark$ & $\checkmark$ & $\checkmark$ \\
\hline 2.Deseñar proxectos en todas as súas fases & $\checkmark$ & $\checkmark$ & $\sqrt{ }$ \\
\hline 3.Traballar colaborativamente & $\checkmark$ & $\checkmark$ & $\checkmark$ \\
\hline 4.Comunicación efectiva & $\checkmark$ & $\checkmark$ & $\checkmark$ \\
\hline 5.Expresión & $\checkmark$ & $\checkmark$ & $\checkmark$ \\
\hline 6.Ser cidadáns responsables & $\checkmark$ & $\checkmark$ & $\checkmark$ \\
\hline 7.Toma de decisións e solución de problemas & $\checkmark$ & $\checkmark$ & $\sqrt{ }$ \\
\hline 8.Capacidade de pensamento crítico. Autocrítica & $\checkmark$ & $\checkmark$ & $\checkmark$ \\
\hline 9.Crecer a través da experiencia & $\checkmark$ & $\checkmark$ & $\sqrt{ }$ \\
\hline 10.Crecer en autoestima e autoconfianza & $\checkmark$ & $\checkmark$ & $\sqrt{ }$ \\
\hline 11.Recoñecer o seu potencial & $\checkmark$ & $\checkmark$ & $\checkmark$ \\
\hline 12.Sentido da responsabilidade & $\checkmark$ & $\checkmark$ & \\
\hline 13.Empatía & $\checkmark$ & $\checkmark$ & \\
\hline 14.Ser autónomo e emprendedor & $\checkmark$ & $\checkmark$ & \\
\hline 15.Ser tolerante & $\checkmark$ & & \\
\hline 16.Aprender de aqueles que son descoñecidos & $\checkmark$ & & \\
\hline
\end{tabular}

Táboa 5. Competencias detectadas nos diferentes proxectos

\section{CONCLUSIÓNS}

As ferramentas metodolóxicas ApS e ABP mostráronse moi útiles para a avaliación das competencias transversais da materia Fundamentos de Física. Dende o punto de vista académico todos os estudantes adquiriron as competencias esperadas e a maiores 
detectáronse outras. As vantaxes da aprendizaxe baseado na experiencia, cooperativo e colaborativo, así coma o feito de ter que aprender para ensinar son patentes nas dúas metodoloxías. Tódolos axentes implicados mostraron a súa satisfacción cos proxectos executados. Diferentes metodoloxías e diferentes proxectos promoveron a adquisición de distintas competencias nos estudantes. 0 ApS resultou unha actividade con un grande potencial na que se dota ao estudante de valores, e coa que se poden observar competencias persoais nos estudantes moi difíciles de traballar con outras metodoloxías. 0 alumno aprende sendo útil aos demais, o que da como resultado enxeñeiros responsables coma profesionais e coma cidadáns comprometidos.

\section{REFERENCIAS}

Bobroff, J. \& Bouquet, F. (2016). A project-based course about outreach in a physics curriculum. European Journal of Physycs, 37 (045704), pp. 1-10.

Dienhart, C., Maruyama, G., Snyder, M., Furco, A., McKay, M.S., Hirt, L \& Huesman, R. (2016). The impacts of mandatory service on students in service-learning classes. Journal of Social Psychology, 156 (3), pp. 305-309.

Houlobova, R. (2008). Effective teaching methods- Project-based learning in physics, USChina Education Review, 5 (12), pp. 27-36.

Latib, A.A., Amin, N.F., Saud, M.S. \& Kamin, Y. (2017). Impact of Service Learning Program to the University and the Community. Advanced Science Letters, 23, pp- 596-599.

Pinar, C, Onder, F. \& Silay, I. (2011). The effects of problem-based learning on the students'success in physics course. Procedia-Social and Behavioral Sciences, 28, pp. 656600.

Seban, D. (2013). The impacto of the type of projects on preservice teachers ' conceptualization of service learning. Teaching and Teacher Education, 32, pp. 87-97 
Whitley, C.T. \& Yoder, S.D. (2015). Developing social responsibility and political engagement: Assesing the aggregate impacts of university civic engagement on associated attitudes and behaviors. Education, Citizenship and Social Justice, 10 (3), pp. 217-233 